"It is in the particulars, the nuances, the overwhelming variety of ways that we express ourselves that one can come to understand what it means to be a musical human" (Levitin, 2008, front cover).

\title{
EXPLORING THE MUSICAL CULTURE OF AN AFRICAN AMERICAN CHILD WITH DEVELOPMENTAL DISABILITIES IN GROUP MUSIC THERAPY
}

\section{Birth of the Study}

Culture and the ways it affects how a person lives and interacts with the world have always fascinated me. I was born and raised in an American household of European descent going back many generations. In my family, there was a strong emphasis placed on Roman Catholic ideals of acceptance and love for all people. As a result, I see connecting with others, regardless of their cultural values, as a chance to have a new experience, a new connection, and a richer, deeper life. This ability to connect with others from different backgrounds is also what led me to the field of music therapy. Now, I am pursuing my graduate degree in Music Therapy.

The music therapy program I am involved in has given me the opportunity to intern this year at a school that provides alternative education programs for children up to the age of 5 who have developmental disabilities. At the school, children's culture, particularly their musical culture, seems to influence how they interact with the world and what their needs might be in terms of music therapy.

During my clinical training, I have encountered mostly African American clients. This has inspired me to explore more about this culture, particularly in terms of music. Such an exploration would help me and others in the field of music therapy to better serve the African American population. As of 2010, African Americans make up approximately $12.6 \%$ of the U. S. population (U.S. Census Bureau, 2010). Thus, it can be implied that a percentage of this population makes up a prominent amount of the music therapy clientele in the U.S.

In this study, I examined the specific musical culture of an African American child in group music therapy. I utilized qualitative methods in an early childhood education setting. Data was gathered from interview questions sent home to the parents and guardians of the children in the group and from the clinical session. The study also explored which connections, if any, existed between the participant's musical culture and the therapeutic process. The therapeutic process includes the ways in which the children respond to and engage with the therapist and each other through the music, in order to work toward therapeutic goals. Thus, it was necessary to study the musical cultures of the African American child as well as the other group members. Other group members' ethnicities included Caucasian American, Hispanic American, and Pakistani.

For the purposes of this study, musical culture is defined as a combination of: (1) individual culture based on preferences, personality, and upbringing; (2) family culture; (3) community culture; (4) culture of the country in which the child resides; (5) culture of the broader ethnicity or race with which the child identifies; (6) co-creative music therapy culture, including interaction with the therapist's culture and (7) cultural conditioning and imprinting that results from interaction with cultures of other group members and myself as the therapist. 
This study is extremely relevant to the field of music therapy. There has been very little research conducted on ethnicity or race and how it influences a client's musical culture and the music therapy process (Rilinger, 2011, p. 78). This study will serve as a catalyst for future research on the topic of ethnic and racial culture in the field of music therapy, particularly in terms of qualitative research.

\section{LITERATURE REVIEW}

After reviewing existing literature in the areas of musical culture and music therapy, there was found to be a dearth of research conducted on this topic. According to multiple studies and articles by Chase, Darrow, Moreno, Shapiro, and Toppozada, "the majority of music therapy articles on cultural competency address general principles" (as cited in Rilinger, 2011, p. 78), rather than topics which are specific or in depth. Still, literature, such as research articles (Forrest, 2001; Morrison \& Demorest, 2009; Swijghuisen Reigersberg, 2010; Williams \& Abad, 2008) and textbooks (Dileo, 2000; Yalom, 1995), has been written on areas that relate to the topic of culture in music therapy and other professions. This literature review will deal specifically with culture in terms of ethnicity and race, focusing on three main areas: Music and Culture, Multicultural Considerations in Music Therapy, and Group Music Therapy with Children in Early Childhood Education Settings.

\section{Music and Culture}

Culture can articulate people's values, systems of norms, beliefs and ideologies that give meaning to the lives they live (Forrest, 2001). The first question is; how does culture relate to music? Many can attest that the use of music and its fundamental characteristics is universal in how it helps to shape humanity across cultures and throughout the course of history. Namely, Levitin (2008) describes how all cultures use music to frame core elements such as friendship, joy, comfort, knowledge, religion and love. However, while some aspects of music may transcend cultures, music and culture are highly related (Brown, 2002). Brown (2002) states that "the very act of making and/or performing music may have alternate meanings for clients" ("Music: a Universal Language," para. 6) of different cultures.

Over the course of history, various sources have shared Brown's view, asserting that the meaning and expression of music, can often be culturally specific (Miller \& Shahriari, 2009; Morey, 1940; Morrison \& Demorest, 2009). According to Miller and Shahriari (2009), "musical expression is both culturally specific and culturally encoded with meaning" (p. 3). Similarly, an article (Morey, 1940) conducted several decades back addressed the effect music has on the emotions of people in different cultural groups. The findings indicated that a group of boys from a remote village in Liberia did not respond the same way to Western musical pieces as people from Western culture did. Although the use of music is universal across cultures, it seems that how music is expressed and the meaning of music is culturally specific. A recent study (Morrison \& Demorest, 2009) even found that people's brains functioned differently in response to culturally familiar music as opposed to unfamiliar music. Such enculturated brain interpretations included location of the musical downbeat and recognizing mistuned notes in musical scales (Morrison \& Demorest, 2009). For the purpose of this study, it is therefore important to study music as it relates to the culture of the child at hand. According to Pavlicevic (2003), "As 
individuals, our socially [and culturally] determined roles combust on one another in [music therapy group] sessions. .." (p. 193). Therefore, it is necessary to examine the music of the other group members' ethnic and racial cultures also, as they provide insight for how and why group members interact in certain ways. These races and ethnicities include African American, Caucasian American, Hispanic American, and Pakistani.

\section{African American music}

In order to understand the characteristics of African American music, I will first explore traditional African music. I want to stress here that African American culture is very diverse, and some African Americans have stronger ties to traditional African culture than others do. Still, in terms of music, Sylvan asserts that African American culture of today is rooted in the ancient rituals of Africa (as cited in Viega, 2012).

According to Meki Nzewi (1999), a scholar from the University of Nigeria, the nature of traditional African music is very much defined by cultural practices. In traditional African culture, music is considered a significant aspect of life, especially in childhood, when a person's musical role is cultivated and shaped. When a child is old enough to walk and talk, the child will begin training on an instrument, as well as in singing and dance (Nzewi, 1999). These practices reflect the three most salient features of traditional African music: the use of communal dance, call-and-response singing, and polyrhythm (Miller \& Shahriari, 2009). They also reflect the traditional African value of the communal music experience.

Traditional African dance can take many forms. The most common form is informal dancing that often takes place when large groups of people are gathered for a musical event. In these dances, one member of a group may step out briefly from the crowd to dance, spurred on by cheering (Miller \& Shahriari, 2009). Call-and-response singing is a musical form in which one caller gives a question or prompt in the form of a chant or song, followed by a response from the group (Miller \& Sharhriari, 2009).

In a traditional African ensemble, three layers of music (rhythm) exist. The first is the fundamental layer that provides a continuous and ongoing pulse sense; the second is the "primary. . . strange-feeling layer" (Nzewi, 1999, p. 81) which offsets the pulse sense; and the third is the new, strikingly pronounced, phonic resolution of the other two layers. These lines are interdependent and cannot be separated out as independent entities (Nzewi, 1999). Because there are multiple lines or "rhythms," traditional African musical rhythm is commonly referred to as polyrhythm.

The music of African Americans, although not identical to traditional African music, is inevitably built off of and influenced by traditional African music. This is because culture does not become replaced by a new idea, but rather influenced and "fertilized" by it (Stige, 2002, p. 14). Spirituals, gospel, ragtime, the blues, jazz, rhythm and blues, soul, and hip-hop are some of the main African American musical styles of today (Peretti, 2009). Some African values that can be found in these styles include: a sense of community, found in spirituals, gospel, soul and hiphop; oral tradition, found in hip-hop (Hara, 2012); communal dance, found in hip-hop; call-andresponse singing, found in spirituals, gospel, jazz, and hip-hop (Hara, 2012), and polyrhythm, found in hip-hop, rhythm and blues, and soul.

Hip-hop is a prevalent style of African American music today that ties very heavily into cultural notions (Viega, 2013). It emerged from African American culture and reflects the 
implications of slavery and the long journey from the first years of emancipation to today. The cultural implications of hip-hop on music therapy with clients of this culture will be explored later in this literature review.

\section{Music of the United States}

American music is a very broad category. It encompasses many genres, such as hip-hop, R\&B, rock and roll, blues, bluegrass, jazz, country, pop, techno, barbershop, gospel, soul, European classical, musical theatre, standard ballads and ragtime (Hadley \& Yancy, 2012; Starr \& Waterman, 2009). In a very general sense, music of the United States has been said to emulate America's "wide open geography. . . [and the] sense of personal freedom characteristic of American life" (Ferris, 1993, p. 11), especially in its use of irregular rhythms and long meandering melodies. It is based mainly upon issues of ". . social class, race and ethnicity, geography, religion, language, gender, and sexuality" (The Media Briefing, 2012). Music is also a major part of many mainstream holiday celebrations in America, such as Christmas and Independence Day, as well as other more culturally bound festivals and holiday ceremonies, such as Mardis Gras and St. Patrick's Day.

\section{Hispanic American Music}

Although each Hispanic American culture may be characterized by different types of music, one article (Rilinger, 2011) provides a number of insights about the music of Mexican American culture, which represents $65 \%$ of the Hispanic population in the U.S. In Mexican American culture, children often listen to music in the home that their parents prefer, such as music on the radio, rather than traditional Mexican American children's songs. Music for children in this culture may also be provided in conjunction with a significant holiday or life event such as birth or death. For example, the song "Las Mananitas" (Rilinger, 2011, p. 81) is sung on the morning of a child's birthday.

Popular music of Mexican American culture and general Spanish popular music differs from Western music in that it uses many syncopated rhythms on the offbeat. Stylistically, music of the Hispanic culture may differ from that of Western culture in that fast strumming of minor tones is used to indicate an exciting or arousing mood, rather than a sad mood, as minor tones would indicate in Western culture (Rilinger, 2011).

\section{Music of the Indian Subcontinent}

Music of the Indian subcontinent also covers an array of different styles. Its modern music is a mix of traditional Indian music and Western pop styles (Sarrazin, 2006). Still, traditional Indian music is characterized by an emphasis on melody and rhythm, a single vocalist or instrumentalist with little or no harmony, use of drone, emphasis on chest voice, even in the upper registers, and the use of ornamentation (Sarrazin, 2006). Little notation is used in traditional Indian music.

Rather, it is passed through aural tradition. This music may be reflective of a strong emphasis on family structure and functionality (Sarrazin, 2006). Modern Indian music, such as that represented in the Indian film industry, fuses traditional Indian music with Western pop styles (Sarrazin, 2006).

It is clear that there are some distinct differences among the music of the cultures at hand. Although certain elements of musical phenomena seem to be universal, such as the use of music at important ceremonies or events, music's role in such contexts differs drastically according to culture. As reviewed, music and culture are closely related, and the role of culture is significant 
in music therapy. Thus, it is critical that music therapists are aware of how musical cultures interact in the music therapy process.

\section{Multicultural Considerations in Music Therapy}

According to Cheryl Dileo (2000), the topic of culture and music therapy has not been addressed extensively in the literature, despite the seemingly strong ties between culture and music. She asserts that the problem in music therapy is that while Western psychological structures emphasize individuality and individual expression, Malley and Reilly relay that nonWestern psychological structures place importance on "relationships. . .conformity. . .collective responsibility, [and] control of feelings" (as cited in Dileo, 2000, p. 151). These non-Western ideologies should not be overlooked. Such a view is reflected in an article by Julie M. Brown (2002) which stresses the importance of culturally centered music therapy and the need for music therapists to examine their own world views in order to face and overcome biases.

Since then, several ethnomusicologists have presented similar views which imply that culture centered music therapy is most effective. Bakan (2009) emphasizes the importance of the "situation" (pp. 510-518) of the therapist and client while engaging in music therapy, including their respective cultures. Swijghuisen Reigersberg (2010) goes so far as to present a culturally centered approach in her research. She asserts that using a culturally centered, or ". . .ethnographically informed approach to choral facilitation was able to promote well-being amongst Hopevalian choir members. .." (p. 70) in Northern Queensland. She states that the nature of the choral facilitation is similar to music therapy. Therefore, her findings indicate that considering clients' cultures in music therapy practice is very important for effective therapy. Similar results were found in an article by Kate Williams and Vicky Abad (2008) which used culturally specific approaches that involved extended family life and respect for elders. These approaches seemed to enhance music therapy outcomes for family groups of the Aboriginal culture. Later, the American Music Therapy Association (2012) included the administration of culturally sensitive therapy as part of its professional competencies. Although the music therapy field has expanded its awareness of the need for culturally centered music therapy, it seems there is still a long way to go in terms of implementing such practice. For the purposes of this study, it is necessary to examine the specific cultural implications of the child at hand and how they relate to the music therapy process.

\section{Implications of African American culture and music therapy}

One article by Wheeler and Baker (2010) on music therapists' worldviews relays that music therapists may interpret or misinterpret rhythms, depending on whether he or she is analyzing in accordance with Western or African musical styles. Thus, music therapists may need to become more aware of African musical styles.

It is also crucial for music therapists to be aware of thoughts and ideologies that may be characteristic of clients from African American ethnic or racial cultures. Nzewi's (1999) investigation of music education relays that modern schools in Africa are replacing traditional African musical techniques with European classical music, church songs, and occasional African songs by rote. Nzewi (1999) relays that this ". . . is a radical, de-culturating process which continues to produce. . .crises" (p. 72). Such a view suggests that African traditional culture has and is presently being challenged by Western cultural ideas. If these are views held by people in 
Africa, such views are likely to apply even more heavily to those of African descent living in America. As music therapists, it is important to consider these notions.

Furthermore, the deeply rooted ties of the hip-hop music genre to African American culture help us as music therapists to understand the views of African American clients and how to use music of this culture as a therapeutic agent. Because hip-hop music is so closely linked to cultural notions, Viega (2013) asserts that Hip Hop is a culture of its own. He makes a distinction between "hip-hop. . .the genre of music and the mainstream media associated with rap music" (Viega, 2013, p. 2) and "Hip Hop. . the cultural engagement in the artistic and stylistic elements of hip-hop" (Viega, 2013, p. 2). Hip Hop originated as a culture of young African Americans of urban communities. In fact, Jay-Z (2007) asserts that Hip Hop culture is the essence of black America.

Hip Hop then branched out to people of various ethnic and socioeconomic groups (Lightstone, 2012). Viega (2012) compared Hip Hop's rapid and vast expansion to a "hero's journey" (pp. 58-68) in that Hip Hop culture emerged in areas that had been neglected by their governments. Because of this, it took on an "Orphan" (Viega, 2012, p. 62) persona and went from being innocent to rebellious. Over time, however, Hip Hop began to gain strength through the art of music_-"hip-hop" (Viega, 2013, p. 2) - and used it to overcome obstacles. Such views regarding Hip Hop culture are reflected by KRS ONE (2009), who ties together elements of hiphop music culture (Emceeing, DJing, break dancing, and graffiti writing) with faith in God and overcoming struggles faced by inner city blacks living in America. Jay-Z (2007) also emphasizes this point of view. He conveys that Hip Hop provides hope for "everyone who was born into a life that seems destitute and destined for failure. .." (p. x) According to Korbin and Tyson (2006) such a process may be used with clients of Hip Hop culture as a form of empowerment. Because the child in the study is both African American and a child with a disability, he is faced with multiple struggles and positions of inferiority. As a result, he may connect even more to Hip Hop culture and respond to hip-hop music as a therapeutic agent.

The music of this culture deviates aesthetically from music rooted in traditional European culture. It incorporates a programmed rhythm or syncopated rhyming chant, with a vernacular or slang text difficult for people outside of the Hip Hop culture to understand. This is quite different from the more colloquial terms set to melodies and/or functional harmonies, as in European music (Lightstone, 2012).

Rap music falls under the category of hip-hop music (Viega, 2013). Rap music can be traced back to a traditional African belief in the concept of spoken word to "change and configure reality" (Hadley \& Yancy, 2012, p. xxxi), known as the concept of Nommo. It is rooted in a long legacy of people striving for linguistic agency, self-definition, and a positive sense of self (Hadley \& Yancy, 2012). Rap music is also rooted in an African tradition involving a "griot, the African keeper of ancestral history" (Hara, 2012, p. 5). Elements of this tradition can be seen in some forms of rap music where the rapper speaks about current events and serves to unite his/ her people. As such, Rap music is reflective of African American views and can be used as a therapeutic agent for clients of this culture. It may also be reflective of the views of clients struggling with disabilities.

It is important for music therapists to consider the implications of African American culture in their work with clients. The literature (Nzewi, 1999; Wheeler \& Baker, 2010) suggests 
that current African American perspectives may include recognition of Western ethnocentrism and challenges to traditional African and African American values. Since hip-hop music emphasizes the values of this culture, this music may be a useful therapeutic agent for African American clients. Also, because some of the struggles of inferiority that African Americans face are similar to struggles perceived by clients with disabilities, hip-hop music may be even more appropriate for African American clients with disabilities. Still, music therapists should explore various musical ways to reach clients of this culture therapeutically.

\section{Music Therapy with Children in Early Childhood Education Settings}

In order for music therapists to understand the role of musical culture in music therapy with children in this setting, it is essential to explore the literature regarding music therapy with this population. Most studies of children in early childhood settings seem to involve specific case studies, rather than a group of children. However, one source (Yalom, 1995) provides useful information about the implications of group music therapy in any context. Yalom (1995) asserts that "from whatever perspective we study human society - whether we scan humanity's broad evolutionary history or scrutinize the development of the single individual — we are all at times obliged to consider the human being in the matrix of his or her interpersonal relationships" (p. 17). Thus, the group setting is representative of how individuals truly live in society, and it eventually becomes a social microcosm. As a result, cultural aspects are likely to play a part in group music therapy. These aspects contribute to how group members interact in the world and in turn, within the group.

In addition to sources regarding group music therapy, there are many sources (DermanSparks, Tanaka-Higa, \& Sparks, n. d.; Schwarts, 2008; Trainor \&Corrigall, 2010) which provide useful information about levels of development in young children. For the purposes of this study, it is important to reflect on sources that deal with ethnic development and musical development in young children. These factors are useful to determine the musical cultures of the participants and how these cultures interact.

\section{Levels of musical development in young children}

Schwartz (2008) provides a great deal of information about the developmental levels of children in music, as well as where and why deficits might be seen. She suggests that when working with children, music therapists need to "be playful," (p. 125) and one of the fundamental elements of play is that it "has meaning to the child" (p. 125). Because culture can articulate ideologies that give meaning to people's lives (Forrest, 2001), culture may influence how children make meaning in musical play. Similarly, Trainor and Corrigall (2010) describe children's levels of musical development, particularly in terms of rhythm and pitch. Maintaining a thorough understanding of a child's level of development may make it easier to differentiate cultural factors from developmental factors in music therapy.

\section{Levels of ethnic development levels in young children}

How young children understand ethnic and racial culture may also come into play when

exploring musical culture in this setting. Young children ages 3-5 are said to have limited awareness of race and ethnicity (Derman-Sparks, et al., n.d.). They tend to rationalize thoughts regarding race and ethnicity based on previous experiences and clearly defined rules of statement. Children of this age also tend to identify race and ethnicity based primarily on 
physical characteristics, such as skin color, and secondly on cultural characteristics that can be seen and heard, such as clothing or language (Derman-Sparks, et al., n.d.). It is clear that children of this age are just becoming aware of race and ethnicity, but do not have a clear picture of it. Thus, they're musical culture is likely to be influenced by their natural environment and genetic personality traits, rather than ethnic or racial choices they make.

The literature suggests that culture and music are intricately interwoven, and that culture is therefore likely to play a role in music therapy, particularly in a group setting. Despite this implication however, there is very little research in music therapy that investigates cultural implications, particularly in terms of African American culture, which is quite pervasive in the United States (U.S. Census Bureau, 2012). Therefore, there is a strong need for research of this nature in the field of music therapy.

\section{PROBLEM STATEMENT}

The purpose of this study is to examine how the musical culture of an African American child with developmental disabilities plays a role in the group music therapy process. Subordinate questions include:

(1) What are the characteristics of the African American child's musical culture?

(2) How does the child's musical culture affect the therapeutic process?

\section{METHOD}

I examined four students in a group music therapy session using a naturalistic inquiry design (Denzin, 1978). I focused specifically on a child of African American descent, and studied his musical culture using two types of data: (1) interviews that were sent home to parents regarding music in the home and (2) analyzing a recording of the clinical session which showed how the child interacted in group music therapy. The study then used these same two data sources to explore interactions among the African American child, the therapist, and the other group members, thereby determining how the child's musical culture may have influenced the therapeutic process.

\section{Design}

Due to the unique nature of the school where the study took place, mainly its rich and stimulating sensory environment and the collaborative nature of the staff, a naturalistic inquiry (Denzin, 1978), free from rigorous laboratory conditions, seemed to be the best design for this study. The nature of design in a naturalistic inquiry is an emergent one, unlike in a quantitative paradigm (Aigen, 2005, p. 357), which indicates that changes may be made as the study is conducted.

Although the school has multiple sites, the site where I conducted this study does not have students who receive music therapy as a related service on their Individualized Education Plans. Therefore, all students at this site receive group music therapy. As such, for the purposes of this study, I utilized group music therapy. This would represent music therapy in its natural form at this site. 


\section{Participants}

A music therapy group of four members was created for the purposes of the study. Consent forms were sent out to the parents or guardians of all group members, delineating the characteristics of the research group. In a naturalistic inquiry, a purposive sample "is more likely to hold the answer to specific research questions, concerns, or interests" (Aigen, 2005, p. 355). While choosing an existing group would have been most conducive to the children's natural setting within the school, no existing group's parents and guardians unanimously showed interest in the study. Therefore, a group of four members was chosen from the afternoon classes at the school where the study was conducted, according to ethnicity and race. The group was chosen to represent the four most prominent ethnicities and races of the school and to represent the natural group setting. I specifically focused on an African American child, who I will call "Sam." I chose Sam based on his ethnic and racial background and a recommendation by the on-site supervisor. Because the school is made up of approximately one-third African American children, I chose a child that was a member of the African American ethnicity and race.

The group consisted of four children, ages 4-5, who have developmental disabilities, including speech and language needs, behavioral and psychosocial needs, motor functioning needs, and slight cognitive delays. All interpretations and analyses of data took these factors into consideration.

\section{Introducing Sam and group members: Jay, Kyle, and Logan}

The group members, who I will call "Sam," "Jay," "Kyle," and "Logan," were selected from 12 students whose parents and guardians showed interest in the study. These four boys were chosen because out of the combinations available to represent all four races and ethnicities in the school, these four have the most similar functioning levels. This represented a natural class setting, where placement is based on functioning level. Also, in this group, I interpreted that cognitive functioning was relatively high. This was necessary for the group members to process certain musical complexities that were explored in the study, i.e., the difference between straight rhythm and syncopated rhythm. Finally, because I wanted to focus specifically on musical culture, I chose the most homogenous group in terms of other factors, e.g., gender and age. All of the participants were male and were 4-5 years old.

Sam, age 4, is a bright, sociable African American boy, whose mother is reportedly from the Bronx, NY. At home, his family speaks English and his religion is not specified. He is diagnosed as a preschooler with a disability, and was placed in a $51 / 2$ hour integrated class setting. He receives occupational therapy and play therapy services, indicating sensory, fine motor and psychosocial needs. In music, he usually presents with high energy and a lot of movement. These movements, at times, may present as impulsive, but when embedded in music, they are extremely rhythmic. He seems to enjoy dancing and moving to music, as he often responds to musical activities with positive affect and engagement with therapists and peers. He sings often and sings expressively. His pitch and lyrics are not always accurate, but they are usually rhythmically accurate or at least within the rhythmic pulse of the music. At home, his mother encourages him and his younger sister to play the guitar.

Jay, age 4, is a sweet, friendly Hispanic boy, whose parent moved from Ecuador to the U.S. within the past 5-10 years. At home, his family speaks Spanish and identifies as Evangelical. He is diagnosed as a preschooler with a disability, and he was placed in a $51 / 2$ hour 
integrated class setting. He receives a high frequency of speech therapy services, indicating relatively high speech and language needs. In music, he expresses himself freely, singing and participating with others. His rhythmic sensibilities are sometimes accurate, but at times, he lags behind the beat in his responses.

Kyle, age 5, is a tall, sweet Pakistani boy, whose parent moved to the U.S. from Pakistan within the past 10 years. He is usually quiet and reserved. At home, his family speaks Urdu and Punjabi, and identifies as Muslim. He is diagnosed as a preschooler with a disability, and was placed in a $21 / 2$ hour integrated class setting. He receives speech therapy and occupational therapy services, indicating speech, language, sensory, and fine motor needs. In music, he looks to the other children and seeks social interaction by following along with the therapist or with what other children are doing. At times, he struggles in responding to rhythms through motor function.

Logan, age 5, is a tall, bright Caucasian boy, whose mother is from the U.S. At home, his family speaks English and identifies as Catholic. He is diagnosed with Pervasive Developmental Disorder, Not Otherwise Specified, and he was placed in a $51 / 2$ hour integrated class setting. He receives occupational therapy and speech therapy services, indicating fine motor, speech, and language needs. In music, he expresses ideas when called for and follows directions. He is sometimes rhythmically inaccurate and has a tendency to become distracted.

\section{Myself as a participant}

$\mathrm{I}$, as the music therapy intern and researcher, was considered a participant in this study, because I have a particular musical culture. I have been working as a music therapist with the children in the study since the Fall of 2011. I also have prior experience observing music therapy sessions in early childhood settings in previous semesters. My musical culture is rooted in my upbringing, personality, and the ethnic and racial cultures of the United States. This was likely to have influenced interactions in the group in much the same way the other group members' musical cultures did. Thus, throughout the study, I examined my own musical culture within the group context, and how it interacted with the other musical cultures in the group, particularly that of Sam's culture.

\section{Materials and Setting}

All musical and environmental materials needed for the study were available for use at the school. The session took place in a classroom setting where a small circle of small plastic chairs were set up. Instruments and props brought into the classroom from another room. I, as the music therapist, adhered to the group goals when developing interventions for the session. Interventions involved group improvisational activities embedded with pre-composed music, and instruments and props were chosen based upon these. The instruments and props available for selection included a guitar, keyboard, hand drums, a large round conga drum, wrist bells, maracas, chimes, hand cymbals, scarves, tone chimes, tone bars, cabasas, metalophones, and marimbas. Due to limited resources, I was unable to bring traditional African instruments, such as traditional African shekeres, a "donno" (double-headed hour glass shaped drum), a talking drum, or a single piano (kalimba/mbira) (Miller \& Shahriari, 2009), to the session. However, I was able to utilize instruments that resembled these, such as a mini djembe drum and plastic 
maracas. Furthermore, I used media resources, mainly YouTube videos, to orient myself to a variety of musical cultures and to include an ethnographic component.

\section{Procedure}

Once the group was formed, interview questions were sent home to caregivers. The questions addressed group members' musical traditions in the home as they relate to the child in the group. In order to study Sam's musical culture in a specific way, I decided to examine musical sources that represent the musical genres he is exposed to in his home. I chose these sources based on the interview answers.

After this, a session was conducted following a music therapy structure that was designed to be flexible in session. This music therapy structure was based off of my understanding of music therapy with children (Schwartz, 2008). It also included pieces of cultural music that I either composed or included based on findings in the literature. I infused elements from each of the group members' ethnic cultures (Ferris, 1993; Hara, 2012; Miller \& Shahriari, 2009; Rilinger, 2011; Sarrazin, 2006) so as to see how the African American child responded to elements of his own supposed culture and to that of others. These responses would help determine the musical culture of the African American child, and how this culture played out in the therapeutic process. The session was then videotaped and transcribed. A review from the on-site supervisor, who was present in the session, was conducted to ensure trustworthiness (Aigen, 2005). Trustworthiness involves using multiple reviewers to examine the data, such as on-site supervisors and staff members, in order to uphold standards of credibility, transferability, dependability, and confirmability (Aigen, 2005). Although I had originally intended for several staff members to be present during the study, the school was short-staffed and only an on-site supervisor was present for the research. Finally, for the purposes of the clinical work, I utilized information from charts and Individualized Education Plans, as well as discussion with staff members.

\section{Data Analysis}

\section{Music resources chosen to represent the interview answers}

Two sources of data were collected and analyzed to determine a composite picture of Sam's musical culture. The first source included interview questions from parents or guardians. Based on the answers to the interview questions, I investigated several musical genres. I chose artists to represent each genre. The artists chosen were based on record sales, Grammy awards, and sources relaying that these were influential artists in their respective genres (Billboard.com, 2012; Grammy.com, 2012). After choosing the artists, I then chose a song to represent each artist's most popular work, based on record sales and sources which relayed that these songs were influential works of the artists at hand. I then listened to each song several times, jotting down musical elements, such as rhythm, meter, or vocal qualities for each song. I compiled the elements, choosing the essential elements which would represent each genre. I then identified salient characteristics of Sam's musical culture.

\section{Clinical data}

The second source was clinical data from the session. The clinical data was analyzed according to a phenomenological framework informed by Creswell (2007). The following steps were adapted from Giorgi (1985) and Kim (2008) and modified according to my study: 
(1) The clinical session was videotaped in its entirety by the therapist.

(2) The session was then viewed and transcribed.

(3) The transcription was then read several times to understand instances and interactions in the session, and to begin to note cultural factors; i.e., the salient features characteristic of Sam's musical culture.

(4) The session transcript was then culled: Any reflective, interpretive, or descriptive redundancies and any instances not directly related to the cultural phenomenon were eliminated.

(5) The session transcript was then reviewed and instances of significance, "clusters of meaning," (Creswell, 2007, p. 61) in relation to Sam's musical culture was coded. Instances of significance were coded as those which related to the salient features of Sam's musical culture. Instances related to Sam's disability or related to my own cultural biases or limitations as a music therapist were coded differently. Codes were based on my knowledge of music therapy and disability in early childhood settings, as well as the expertise of my supervisor and the staff.

(6) Instances of significance were then reviewed by an on-site supervisor who was present during the session to confirm their accuracy.

(7) From the instances of significance, categories were extracted, such as "instances related to musical culture" or "instances related to disability."

(8) The categories were then examined and conclusions were drawn regarding musical culture and how it influences the therapeutic process.

(9) A composite passage was then written about the "essence of phenomenon" (Creswell, 2007, p. 62) to increase the therapist's understanding of musical culture and its role in the music therapy process.

(10) Both the original transcript and composite passage were compared to confirm accuracy.

\section{Researcher Perspective and Biases}

As previously mentioned, I am a Graduate Student in music therapy, born and raised in the United States. Although my experiences doing clinical work for my graduate degree have deeply broadened my cultural understanding, my scope remains fairly narrow, and I am aware that such limitations were likely to come into play during the study. For this reason, on-site supervision and collaboration with staff played an active role in my clinical work and interpretation of events during this study.

As mentioned, Wheeler \& Baker (2010) explained that therapists may interpret or misinterpret rhythms, depending on whether they are analyzing in accordance with Western or African musical styles. Despite my attempt to study and learn many African rhythms in preparation for this research, because of my strong Western musical views, I may have interpreted rhythmic responses and portrayed rhythms in a skewed or stilted way. Similarly, having such a strong upbringing in Western musical elements, my movements may have inherently reflected Western ideals. As such, my movements were likely to be very lyrical in nature, as I am not heavily familiar with African dance and movement, or even with hip-hop dance movements. 
Furthermore, my preference for more mainstream, popular hip-hop music has limited my awareness and interpretation of hip-hop music. Up until this point, I viewed older, classic style hip-hop as being more provocative music and therefore, I was rather dismissive of it. Since I am in the role of therapist and model, these biases may have consciously or unconsciously been noted by the clients as insensitivity to African American cultural values (Nzewi, 1999) and/or the values of the other group members.

Still, because I listened to many musical sources to help shed light on African American musical culture and because I included some of these elements in the clinical session, I intuitively noticed that I had a greater musical connection with Sam in the session. I believe I now have a greater understanding and awareness of how to use music to help him reach goals of self-regulation and to better connect with others in a group setting.

As the therapist in this study, I provided all of the music experiences with the intention of helping the group members meet the goals developed for the group. Any information gleaned regarding my topic will therefore be a natural by-product of the group music therapy process at the school.

\section{RESULTS}

Based on the findings, I divided the results into three main categories: (1) Summary of the Clinical Session, (2) Characteristics of Sam's Musical Culture, and (3) Sam's Musical Culture and the Therapeutic Process.

\section{Summary of the Clinical Session}

The session explored group connectivity and progress toward group goals through various musical activities and interventions. The group goals were: (1) self-regulation (2) peer relatedness, and (3) reciprocal play with music therapist and/or peer. The first music activity featured "Come Gather Together" (Schwartz, 2012). The children clapped along to the beat of the song. A transitional song, "Something's A little Bit Different" (Schwartz, 2012), was then used. For this activity, all were quiet and still, except for Sam, who swayed back and forth in his chair. Then, during the second activity, "Let's Play Today" (Cork), Sam initiated a musical idea that seemed to hone the group's musical energies. In "Will You Come?" (Schwartz, 2012), the children marched on the beat and were able to jump on beat while standing up. Aside from Sam, the group members had some trouble finding the beat during the running section. "Can You Do What I Do?" (Cork) brought about the most sustained moment of group connectivity observed in the session. The final activity, "La Bamba/I Like to Dance with My Friends" (Cork), featured a verse in Spanish and a syncopated rhythm on the guitar, with maracas. Here, the group seemed disconnected. The session ended with a traditional line up song. During the session, there were several moments of therapeutic growth and there was a moderate degree of progress toward group goals.

\section{Characteristics of Sam's Musical Culture}

Sam's musical culture is characterized by three main musical elements: emphasis on a strong rhythmic pulse, emphasis on movement, and singing or chanting as a means of 
expression. The following sections categorize data into two parts: (1) Data from the interview questions and (2) Data from the clinical session.

\section{Emphasis on a strong rhythmic pulse}

Data from the interview questions. Sam's mother reported five main genres as being those that Sam is exposed to in the home. The genres included R\&B, hip-hop, reggae, gospel and children's play songs. One characteristic that all genres have in common is a strong rhythmic pulse, often in 4/4 meter. Four of the genres emphasize rhythm, so much so that elaborate rhythms, including syncopated rhythms, are often used. R\&B, hip-hop, reggae, and gospel genres utilize syncopated rhythms that typically accent beats two and four. In contrast, children's play songs often incorporate simpler rhythms, with emphasis on the downbeat.

Data from the clinical session. One of the most prominent responses from Sam in the session was his tendency to respond rhythmically. When I presented a strong rhythmic structure, particularly with an external mechanism keeping the pulse and when the rhythm was straight rather than syncopated, Sam's body responded to the beat provided in the music. His body reflected a sense of rhythm more often than any of the other group members. Such a response is illustrated in the following excerpt from the session.

Vignette 1: I begin playing "Let's Play Today" (Cork)1, in the key of G with a twelve-bar blues bass ostinato that is repeated throughout the piece, which provides a straight 4/4 pulse. As I begin to play and sing, Sam pauses for a moment, and then in response to Logan's impulse to strike the egg shaker on the chair, Sam's strikes as well along to the pulse of the song. He also initiates chanting, "ow ow ow ow" on the beat. The others, who were previously off beat or seemingly distracted, join him and soon, all are playing together along to the pulse of the song.

\section{Emphasis on movement}

Data from the interview questions. Another characteristic of Sam's musical culture is emphasis on movement in relation to the beat provided in the music. When I explored the five musical genres that the answers to the interview questions provided, I found that three of the genres prominently emphasize the use of movement and dance, while two of the genres have less of an emphasis on movement. Hip-hop emphasizes movement in its strong association with break dancing, while reggae music emphasizes movement in its strong association with dance clubs and dance hall music. Children's play songs emphasize movement in that they provide an impetus for focused and/or directed movements in children. However, it seems that because all of the genres have a strong emphasis on rhythm, they all provide a forum for movement in some way (Trainor \& Corrigall, 2010).

Data from the clinical session. During the session, I observed that Sam's movement seemed to be strongly characteristic of his musical culture. For Sam, movement and rhythm seemed to be directly connected. When a strong rhythmic pulse was presented, Sam's body almost always moved to the beat, regardless of what he said or seemingly thought at the moment, as opposed to the other group members, who responded to the beat only sometimes during the session. The following excerpt provides a good example of this response:

\footnotetext{
1 "Let's Play Today" (Cork) is a blues song that I composed for clinical purposes during my internship at the school.
} 
Vignette 2: I begin to sing "Something's A Little Bit different" (Schwartz, 2012)2 in 3/4 meter. Although I do not keep every pulse with a gesture, when there is a rest, I keep the pulse by clapping on beats two and three, as in "Something's a little bit different. (Clap Clap) Something's a little bit strange. (Clap Clap)." The children attend quietly as I sing. All are still in their chairs except for Sam, who sways in his chair back and forth to the beat.

\section{Singing or chanting as a means of expression}

Data from the interview questions. The other main characteristic of Sam's musical culture is singing or chanting as a means of expression. The exploration of the five musical genres of Sam's family's musical culture revealed that all of the genres emphasized singing as a means of expression. R\&B uses vocal timbre to emphasize emotional expression. Hip-hop and reggae music often use strong and/or controversial lyrics as means of expression, while gospel music uses dominant vocals, harmony, and spiritual lyric messages as means of expression. Finally, children's play songs utilize simple melodies and functional lyric language so that children can use their voices in order to express themselves.

Data from the clinical session. Similarly, the clinical data revealed that singing or chanting as a form of self-expression is a musical element that Sam can relate to. Throughout the session, Sam often used his voice freely in the music, and he responded with a positive affect, laughing and giggling, when the music called for him to vocalize. The following excerpt from the session illustrates this response:

Vignette 3: I begin the activity "Can You Do What I Do?" (Cork). ${ }^{3}$ This utilizes a bass ostinato that gives a strong pulse in 4/4 meter. It features a melodic theme built on the Middle Eastern scale (Nordoff \& Robbins, 2007). Once this melodic theme is heard, a call-and-response technique is then employed, in which each person takes a turn being the caller, making a sound for the rest of the group to imitate. I take the first turn, modeling a sound. I then facilitate turns going around the circle. A few times, Sam initiates an idea during Kyle's turn, in a seeming attempt to overshadow Kyle. However, when Kyle does initiate a sound, Sam then becomes the answerer and imitates this sound. He does this for the other turn-takers as well. He smiles and giggles as he hears the other children's ideas, and when he is the caller, he makes a "sss" sound, moving his head in slow movements, in seeming representation of a snake, and next, a "Chug chug choo choo" sound, which is rhythmically in line with the ostinato. With this, he moves his feet to the beat and moves his hands in a rolling motion. He beams as the others imitate him.

\section{Sam's Musical Culture and the Therapeutic Process}

In order to assess how Sam's musical culture influenced the therapeutic process, I decided to explore specifically how the three main elements of Sam's musical culture took effect in the therapeutic process. The therapeutic process is defined as the ways in which the children

2 "Something's a Little Bit Different" (Schwartz, 2012) is a song composed by the music therapists at the school for the clinical purpose of transitioning or adjusting to a change.

3 “Can You Do What I Do?" (Cork) is a piece that I composed for the purposes of this study. 
respond to and engage with the therapist and each other through the music, in order to work toward therapeutic goals.

\section{Emphasis on a strong rhythmic pulse and the therapeutic process}

The emphasis on a strong rhythmic pulse seemed to influence the therapeutic process in a way that promoted therapeutic growth. On most occasions, strong rhythmic structures seemed to be associated with participation in musical activities and musical engagement among the group members, thereby allowing the group to make progress toward group goals of peer relatedness and reciprocal play. It also helped to organize and focus responses, thereby allowing for selfregulation. For Sam, the strong sense of rhythm in his body seemed to engage him in a way that helped him overcome tendencies that reflect his needs and disability. Although not all children had responses to rhythm as strong as Sam's, the group dynamics that occurred when a strong rhythmic structure was presented seemed to allow this element to have a positive influence on the therapeutic process (See Table 1).

Table 1

"Will You Come:" 4 Sam's Response to Rhythm Positively Influences the Therapeutic Process

\begin{tabular}{|c|c|c|c|}
\hline Significant event & Therapist's response & Sam's response & Group's response \\
\hline $\begin{array}{l}\text { I present a strong } \\
\text { rhythmic structure in } \\
\text { the running component } \\
\text { of "Will You Come"* } \\
\text { (Schwartz, 2012). I } \\
\text { model this structure } \\
\text { through leg movements } \\
\text { at a strong, fast beat of } \\
130 / 100 .\end{array}$ & $\begin{array}{l}\text { I speed up the beat to } \\
\text { hone Sam's attention } \\
\text { through change. When } \\
\text { I see him and the group } \\
\text { members responding, I } \\
\text { continue on, keeping } \\
\text { the fast beat, and I } \\
\text { present with positive } \\
\text { affect. In response to } \\
\text { Sam touching Kyle's } \\
\text { knee, I say, "Hands to } \\
\text { yourself" quickly, and } \\
\text { move on. }\end{array}$ & $\begin{array}{l}\text { Sam responds to the } \\
\text { change in tempo by } \\
\text { running approximately } \\
\text { on beat throughout the } \\
\text { verse, smiling and } \\
\text { looking toward Kyle. } \\
\text { At one point, he even } \\
\text { touches Kyle's knee. } \\
\text { When I verbally cue } \\
\text { him, he removes his } \\
\text { hand. As we move into } \\
\text { the chant, he } \\
\text { participates } \\
\text { enthusiastically. }\end{array}$ & $\begin{array}{l}\text { Logan and Jay attend } \\
\text { to me. Both lag behind } \\
\text { the beat with leg } \\
\text { movements. Kyle } \\
\text { attends at times to me } \\
\text { and at times, to Sam. } \\
\text { He looks to Sam with a } \\
\text { slight smile as Sam } \\
\text { touches his knee. He } \\
\text { makes sporadic leg } \\
\text { movements. Then, we } \\
\text { chant together. }\end{array}$ \\
\hline
\end{tabular}

\section{Emphasis on movement and the therapeutic process}

Utilizing the element of movement in relation to the rhythmic elements of the music seemed to enhance the therapeutic process. It seemed that movement brought several issues to the surface for the group, thereby heightening the group's awareness of one another. Some of these issues involved whether to join or go against the group, or whether to follow me or a group member. At times, it connected the group and at times it brought out the group members' differences. It

4 "Will You Come?" (Schwarts, 2012) is an adaptation of "She'll Be Comin' Round the Mountain," an old American worker song. 
seemed to foster growth as each group member tried to navigate and hold their own as individuals within this social microcosm. Thus, this element allowed the group to make progress toward goals on a deeper level (See Table 2).

Table 2

“Will You Come:” Sam's Response to Movement Positively Influences and Deepens the Therapeutic Process

\begin{tabular}{|c|c|c|c|}
\hline Significant event & Therapist's response & Sam's response & Group's response \\
\hline $\begin{array}{l}\text { I present the jumping } \\
\text { component of "Will } \\
\text { You } \\
\text { Come?" (Schwartz, } \\
\text { 2012) }\end{array}$ & $\begin{array}{l}\text { During this component, } \\
\text { I switch to } 3 / 4 \text { time. I } \\
\text { then model "jumping," } \\
\text { which involves moving } \\
\text { my legs up and down } \\
\text { together to the beat } \\
\text { while sitting down, b/c } \\
\text { the clinical intervention } \\
\text { involves sequencing. } \\
\text { First: sitting. Next: } \\
\text { standing. When Sam } \\
\text { initiates standing while } \\
\text { jumping, at first I say, } \\
\text { "Oh, in your chair!" } \\
\text { But, when the others } \\
\text { join him, I continue the } \\
\text { music, supporting the } \\
\text { children's movements, } \\
\text { as jumping in one's } \\
\text { chair may be a struggle } \\
\text { due to their disabilities. }\end{array}$ & $\begin{array}{l}\text { Sam tries to maneuver } \\
\text { the movement with } \\
\text { both legs and does not } \\
\text { move on the beat. He } \\
\text { then gets up and begins } \\
\text { jumping while } \\
\text { standing. He smiles } \\
\text { slightly as his body } \\
\text { seems to find the beat. } \\
\text { His smile widens as } \\
\text { Kyle joins him. He sits } \\
\text { for a moment as I cue, } \\
\text { but then gets back up. } \\
\text { He beams as the other } \\
\text { group members join } \\
\text { him. When we begin } \\
\text { the chant, he says, "I } \\
\text { want to switch chairs," } \\
\text { and then sits back } \\
\text { down, eventually } \\
\text { joining in the chant. }\end{array}$ & $\begin{array}{l}\text { Kyle tries to follow my } \\
\text { movements but ends up } \\
\text { moving only his } \\
\text { bottom out of his chair. } \\
\text { Jay and Logan move } \\
\text { their legs up and down } \\
\text { approx. on the beat for } \\
\text { a few seconds, and then } \\
\text { look at the other two } \\
\text { members. When Sam } \\
\text { stands, Kyle stands } \\
\text { tentatively, but looks at } \\
\text { Sam and smiles. He } \\
\text { follows Sam in sitting } \\
\text { and standing up again. } \\
\text { Soon after, Jay joins in } \\
\text { standing. Logan } \\
\text { distractedly sings in a } \\
\text { silly voice. When he } \\
\text { notices the others, he } \\
\text { too stands. Jay, Sam, } \\
\text { and Kyle beam at each } \\
\text { other, while Logan is } \\
\text { neutral. }\end{array}$ \\
\hline
\end{tabular}

Singing or chanting as a means of expression and the therapeutic process

Generally, the encouragement of free vocals and chants allowed the group forces to work in uncovering the therapeutic process and making progress toward goals. This musical element worked most effectively when I presented a vocal line or chant that contained simple language, repeated vowel sounds, and/or a straight steady pulse, as in the number chant during "Will You Come?" (Schwartz, 2012).

This musical element was also effective when singing or chanting was initiated by the group members themselves, as in the activity "Can You Do What I Do?" (Cork). This allowed for 
peer relatedness, reciprocal vocals through a call-and-response technique, and self-regulation. Similarly, in "Let's Play Today" (Cork), Sam initiated the vocal chant, "ow ow ow ow" that was not conducive to my lyric vocal line, but was more in line with the rhythmic pulse of the music. In this instance, the group members chose to join Sam. Such a group response could reflect a natural transference in the group dynamic to join with each other and diverge from the therapist, because trust in the therapist in this new group setting has not yet been fully developed (Yalom, 1995). Furthermore, the "ow" chant was perhaps more enticing because of its direct correlation with the rhythmic pulse (See Table 3). It allowed Sam and the group members to express that at times, they have ideas that are musical and functional, yet different from my own. However, when the element of singing and chanting was combined with Spanish lyrics and syncopated rhythms in "La Bamba/ I Like to Dance with My Friends" (Cork), the group seemed disconnected and as a result, the therapeutic process seemed stilted.

Table 3

“Let's Play Today:" Sam's response of Chanting as a Means of Expression Positively Influences the Therapeutic Process

\begin{tabular}{|c|c|c|c|}
\hline Significant event & Therapist's response & Sam's response & Group's response \\
\hline $\begin{array}{l}\text { I present a strong } \\
\text { rhythmic structure in } \\
\text { "Let's Play } \\
\text { Today" (Cork), with an } \\
\text { ostinato in the bass that } \\
\text { emphasizes a straight } \\
\text { pulse in } 4 / 4 \text { meter. I } \\
\text { model shaking a bell in } \\
\text { my right hand to } \\
\text { further emphasize this } \\
\text { pulse. }\end{array}$ & $\begin{array}{l}\text { Sam begins striking his } \\
\text { chair with his egg } \\
\text { shaker and chanting. } \\
\text { When I see other group } \\
\text { members responding, I } \\
\text { acknowledge the "ow" } \\
\text { chant, reframing it to } \\
\text { be an expression of } \\
\text { "silliness." I foster the } \\
\text { group musical moment } \\
\text { by then continuing to } \\
\text { sing and play, bobbing } \\
\text { my head to the beat. }\end{array}$ & $\begin{array}{l}\text { As I begin to play and } \\
\text { sing, Sam responds } \\
\text { quickly to Logan's } \\
\text { impulse to strike his } \\
\text { egg shaker on his chair. } \\
\text { Sam strikes along with } \\
\text { the beat, initiating a } \\
\text { chant, "ow ow ow ow." } \\
\text { He beams as the others } \\
\text { join him. He looks at } \\
\text { me and follows as I } \\
\text { move my instrument up } \\
\text { on the V7 chord and } \\
\text { down on the IV chord. }\end{array}$ & $\begin{array}{l}\text { After Sam begins } \\
\text { striking his maraca on } \\
\text { his chair, adding the } \\
\text { vocal chanting } \\
\text { component, the group } \\
\text { members join Sam in } \\
\text { doing this. Shortly into } \\
\text { the structure, their } \\
\text { movements and } \\
\text { vocalizations all fall on } \\
\text { the beat and the group } \\
\text { is musically together } \\
\text { with me. The group } \\
\text { laughs at my joke and } \\
\text { joins me in gesturing } \\
\text { up and down. }\end{array}$ \\
\hline
\end{tabular}

The results of this study revealed that musical culture appears to play a role in the therapeutic process and that if used in certain ways, it can be propelling for therapeutic growth. The sources, including answers to the interview questions and data from the clinical session, indicated that the main characteristics of Sam's musical culture include emphasis on a strong rhythmic pulse, emphasis on movement, and singing or chanting as a means of expression. These sources also indicated that the elements of Sam's musical culture generally affected the 
therapeutic process in a way that brought about therapeutic growth and progress toward group goals. However, when combined with certain elements outside of Sam's musical culture, such as a Middle Eastern scale, his musical culture had more of a positive effect on the therapeutic process than when combined with other cultural elements, such as Spanish lyrics and syncopated rhythms.

\section{DISCUSSION}

Sam's musical culture was characterized by three main elements: emphasis on a strong rhythmic pulse, emphasis on movement, and singing or chanting as a means of expression. Also, Sam's musical culture seemed to have an active and positive role in the therapeutic process. It is important to discuss possible factors that played into these results and what these results may indicate in the field of music therapy.

\section{Emphasis on a Strong Rhythmic Pulse}

One of the most prominent responses from Sam in the session was his tendency to respond rhythmically. He responded to a strong rhythmic pulse in more instances than did the other children. This is consistent with much of the literature regarding African and African American music (Hadley \& Yancy, 2012; Miller \& Shahriari, 2009; Nzewi, 1999) There was, however, one main discrepancy between the clinical data, the data from the music samples I chose to represent the interview answers, and the literature. In the session, Sam seemed to display a stronger response to a straight rhythmic pulse with emphasis on the downbeat, as opposed to the syncopated rhythms suggested by the musical data or the polyrhythms suggested in the literature (Miller \& Shahriari, 2009). This main difference may be due to the fact that Sam's age may make it hard for him to relate to these musical rhythms at this point in his life, as he is only 4 years old. At age 4 , a child can learn to differentiate between simple duple and triple rhythms (Schwartz, 2008) but has not yet developed the motor ability to respond to more complex ones (Trainor \& Corrigall, 2010). Also, Morrison and Demorest (2009) suggest that people of different cultures have contrasting responses based on where the downbeat is placed. Because Sam's age bracket and preschool placement also contribute to his musical culture, he is likely to respond to simpler rhythms with emphasis on the downbeat rather than syncopated rhythms with emphasis on the off beat. He may respond to more complex rhythms as he grows older and associates more with African American cultural norms.

Moreover, because Sam is diagnosed as a child with a disability, he is likely to have even more trouble with motor function as evidenced by his need for occupational therapy, than a typically developing child. The disjunct between being able to mentally recognize a syncopated rhythm, but not being able to respond to it with a motor function, may cause frustrations for Sam. I sense that this may cause him to react at times with obstinate behavior, as in the drumming component of "Will You Come?" (Schwartz, 2012). Here, when presented with a syncopated rhythm, he raised his hand high and struck the drum really hard and out of time. As mentioned, Sam's ability to relate and respond to more complicated rhythms such as these may come later in life. 


\section{Emphasis on Movement}

In addition to a general rhythmic response, Sam responded physically to rhythm more often than any of the other group members. The reason for this is most likely that the other children's cultures may emphasize rhythm, but such an emphasis may be reflected less in their responses because their cultures also place strong emphasis on other elements: pitch, melody, harmony, and instrumental timbres (Ferris, 1993; Rilinger, 2011; Sarrazin, 2006). A strong emphasis on movement and embedding this movement in daily life at a young age is conducive with the traditional African belief that children begin taking part in communal dances at an early age (Nzewi, 1999). This belief carried over to African American musical traditions reflected in hip-hop (Hara, 2012; KRS ONE, 2009). Also, because music is embedded in Sam's daily life, using music of his culture is likely to produce a prominent response from Sam.

\section{Singing or Chanting as a Means of Expression}

Singing or chanting as a means of expression is also related to traditional African values found in the literature, although these values reflect singing and chanting in a very specific form, known as call-and-response singing (Miller \& Shahriari, 2009). According to Hadley and Yancy (2012) and Hara (2012), elements of this call-and-response technique directly carried over to African American values in the gospel and hip-hop genres, where oral tradition still serves to ensure a sense of unity and empowerment. This technique was shaped into singing as more of a general expression of the self in the R\&B genre ("Styles of R\&B," n.d., para. 3). Furthermore, in the hip-hop genre, singing and rapping are viewed as important forms of expression in what is considered to be a suppressive society (Viega, 2012). Vignette 3 showed that Sam responded strongly to expressive song activities, which led to a stronger group response. For example, during "Can You Do What I Do?" (Cork), he was able to take a step toward therapeutic growth by being able to listen when his peers had musical ideas. He was able to modify his own vocal responses to emulate theirs, thereby showing the beginning stages of empathy. This also overrode Sam's tendency to insist on his own ideas.

At times, I presented music that gave Sam the opportunity to use multiple elements of his musical culture, i.e. movement and a strong rhythmic pulse, simultaneously. These opportunities seemed to give Sam strong musical impulses that helped to connect the group musically and increase the group's awareness of one another. Sam's impulse to fully embody all elements of his musical culture at the same time is consistent with traditional African musical characteristics involving the creation of rhythms on various objects, singing, and dancing (Nzewi, 1999). African cultural values weave these elements together as an integral part of a child's life from an early age (Nzewi, 1999).

\section{Other Factors and Considerations with Regard to Sam's Musical Culture}

Aside from Sam's ethnic and racial culture and the qualities of music in his home, other factors that affect Sam's musical culture include the influence of his family life, as well as the influence of his school life, his peers, and the music therapy culture of his school. As reported in the answers to the interview questions, the ways in which music is used in the home show how much his family values music. Music in Sam's home is embedded as a strong part of daily life. His mother encourages Sam and his sister to listen to music and to learn an instrument (guitar). 
Music seems very significant in Sam's family life and as a result, it seems that Sam's responses to music are quite strong.

School life also is a major part of Sam's daily activities. At school, his teacher sometimes uses CDs of traditional American children's songs as learning tools. His music therapy sessions often use music with some elements of traditional children's songs, such as simple, functional language (mostly in English) and repeated melodic and rhythmic phrases. Rhythmic patterns in such songs are usually simple and straight with emphasis on the downbeat. As a result, his brain may function more aptly in response to simpler rhythms with emphasis on the downbeat (Morrison \& Demorest, 2009). The music is culturally open, however, in that it features a variety of different modes and styles. It also encourages musical creativity and interaction among peers. For Sam, this indicates that his musical culture is not limited to only elements of the African American culture, but that the enculturation process at school may also influence his musical culture.

\section{Sam's Musical Culture and the Therapeutic Process \\ Possible explanations for the positive influence of Sam's musical culture}

The results of the study showed that the main elements of Sam's musical culture seemed to generally influence the therapeutic process in a way that was propelling for growth and for meeting group goals of self-regulation, peer relatedness, and reciprocal play. Even though the group members do not all have musical cultures identical to Sam's, the group as a whole seemed to respond to the elements of Sam's musical culture. There could be many possible reasons for this. The first may involve Sam's strong presence and his role in the group. At times, Sam may attempt to draw negative attention, driven by his psychosocial needs. Yet, if the musical pulse is strong enough, it is likely to engage Sam in a positive manner, thereby overcoming his disability and his tendency to disrupt the group. When this happens, Sam's strong response to the music will most likely engage the other group members and lead to group connectivity.

There is another possible reason for the positive influence of Sam's musical culture on the therapeutic group process. The elements of rhythm, movement, and singing or chanting as a means of expression are elements that all the children can relate to in some way, as evidenced by the interview questions and the musical sources. The musical genre that all four group members share is children's play songs. Although Sam seems to respond more strongly to rhythms than the other children, on some level, all of the children are able recognize and respond to simpler rhythms (Schwartz, 2008; Trainor \& Corrigall, 2010). Similarly, because all children can identify with children's play songs, all can respond to singing or chanting to some degree. However, some of the children, such as Logan, who is Caucasian, and Kyle, who is Pakistani, may respond better to melodic structures as a means of expression, as evidenced in the literature regarding the melodic qualities of their music (Ferris, 1993; Sarrazin, 2006). In contrast, Sam and Jay may be more likely to respond to rhythmic chanting as a means of expression, as evidenced by their musical cultures' emphasis on rhythms, including complex rhythms (Miller \& Shahriari, 2009; Nzewi, 1999; Rilinger, 2011).

\section{Discussion of Sam's musical culture combined with other cultural elements}

When the elements of Sam's musical culture were combined with other cultural elements, mixed results occurred. There were two prominent cases that led to such results. One was the activity, 
"Can You Do What I Do?" (Cork) (See Vignette 3) that led to a heightened moment of group connectivity. In this activity, two of the elements of Sam's musical culture were fused with themes based on the Middle Eastern Scale (Nordoff \& Robbins, 2007). There is a possibility that this scale may be associated with Kyle's musical culture, as it uses chromatics and ornamentation (Sarrazin, 2006). For the others, the different nature of the music seemed to draw attention. This activity also featured elements of Sam's musical culture, such as strong rhythmic pulse to organize and ground the music experience, and a call-and-response technique, which allowed Sam to seemingly draw the others into the musical activity with his strong vocal responses. The structural elements of the activity helped to hone the group dynamics in a positive way, so that all of the group members, including Sam, could explore sound and mood qualities that were different from their own. This helped introduce the group members to the beginning stages of empathy.

However, when combined with the cultural element of the Spanish language, as in the activity, "La Bamba/I Like to Dance with My Friends" (Cork), the presence of some of Sam's cultural elements were not able to propel the therapeutic process. Despite my initiation of singing as a means of expression, and emphasis on arm movement through maraca playing, when Spanish lyrics were sung, Sam responded to this activity in a disconnected manner, and was not able to find the beat. The other group members had similar issues with musical connectivity and were not facially attending to one another. However, it is important to note that this activity also utilized a syncopated rhythm, with emphasis on downbeats two and four, which, as previously mentioned, may not have been conducive to the children's developmental age (Trainor \& Corrigall, 2010, p. 101) or to their musical culture as school-aged children. Therefore, their brains likely did not interpret this music as being culturally familiar (Morrison \& Demorest, 2009). The combination of Spanish lyrics, which were unfamiliar to the majority of group members, combined with the lack of straight rhythm on the downbeat, led to stilted therapeutic growth, even though elements of Sam's musical culture were used.

\section{Limitations of the Study and Future Research}

The original procedure was altered as the study unfolded due to the emergent nature of the study (Aigen, 2005, p. 357). Although I had originally planned to analyze several clinical sessions, due to the time constraints of this study, data from only one session was used. More extensive research would help determine how musical culture and the therapeutic process interact over time. Because the study was limited to one session, it was also difficult to utilize the gamut of musical styles that may act as therapeutic agents for Sam. Further research on this topic could expand and utilize other musical styles, such as hip-hop music that could be used therapeutically for clients of African American descent (Hadley \& Yancy, 2012; Hara, 2012, Jay-Z, 2007; Korbin \& Tyson, 2006; KRS ONE, 2009; Lightstone, 2012; Viega, 2012). Furthermore, due to the time constraints and the small scale of this research, the study focused on the musical culture of only one child. A further study would focus on the musical cultures of a greater number of children in music therapy. 


\section{CONCLUSION}

The musical culture of an African American child with developmental disabilities played a significant role in group music therapy process in an early childhood setting. The musical culture of the child, known as Sam, was found to be characterized by emphasis on a strong rhythmic pulse, emphasis on movement, and singing or chanting as a means of expression. The data also indicated that Sam's family uses music as an embedded part of everyday life, thereby leading to strong musical responses in Sam. Thus, due in part to Sam's personality and the way he functions as a strong presence in group settings, the use of the elements of Sam's musical culture generally led to strong positive responses from Sam. This helped to overcome Sam's disability in the moment and kept him from being disruptive in the group. It also helped to involve the other group members in the music and propel therapeutic growth. When multiple elements of Sam's musical culture were utilized, the music was most effective. It was also effective when the elements were combined with an intriguing Middle Eastern tonal center (Nordoff \& Robbins, 2007). It was less effective when used in conjunction with syncopated rhythms and Spanish lyrics.

\section{Implications for Music Therapy Practice}

Musical culture seems to play a significant role in the therapeutic process in a group music therapy setting, and if used in certain ways, it can be propelling for therapeutic growth. As Dileo (2000) asserts, the problem in music therapy is that the construct of therapy is based on Western psychological structures, while other cultural structures that view therapy from a more Eastern, collectivist perspective, are overlooked. Therefore, it is imperative that music therapists working in this field examine where they stand on these ethnocentric perspectives, and that they become aware of their own cultural biases or "situation" (Bakan, 2009, pp. 510-518). It is also important for music therapists working in early childhood group settings to be aware of the musical cultures of group members, and to study the musical elements of these cultures.

Particularly in an early childhood setting, an awareness and understanding of culture is extremely important, as children with developmental disabilities may have limited understanding themselves. The music therapist must also be keenly aware of specific dynamics within the group, as is necessary in any group music therapy setting (Yalom, 1995). This way, the therapist can utilize these dynamics to combine elements of the group members' musical cultures in ways that are most favorable for therapeutic growth.

\section{Implications for Music Therapy Education and Training}

The results of this study indicate that musical culture is a significant aspect in the therapeutic process. Thus, this study calls for more emphasis on culture in music therapy education and training. It specifically calls for emphasis on cultural values toward music, cultural values toward therapy, and the musical elements of culture. Educators and supervisors should seek broader cultural awareness, and should be particularly concerned with the musical cultures of their clients. Then, they can educate supervisees on how to work with such cultures, and on how to become more culturally aware.

Finally, the results indicated that although some conclusions have been drawn to indicate the significance of musical culture in a group music therapy setting with children, there is a great 
need for further research in order to determine more precise ways in which musical culture influences the group music therapy process. Thus, this study serves as a catalyst for future music therapy research. 


\section{References}

Aigen, K. (2005). Naturalistic inquiry. In B. L. Wheeler (Ed.), Music therapy research (2nd ed., pp. 352-364). Gilsum, NH: Barcelona Publishers.

American Music Therapy Association. (2012). AMTA professional competencies (14.5, 16.4, 16.5). Retrieved from http:/www.musictherapy.org/about/competencies/

Bakan, M. B. (2009). Measuring happiness in the Twenty-First Century: Ethnomusicology, evidence-based research and the new science of autism. Ethnomusicology, 53(3), 510 - 518.

Billboard.com. (2012). Music charts. Retrieved from http://www.billboard.com/\#/charts

Brown, J. (2002). Towards a culturally centered music therapy practice. Voices: A World Forum for Music Therapy, 2(1). Retrieved from https://normt.uib.no/index.php/voices/article/ viewArticle/72/62

Creswell, J. W. (2007). Qualitative inquiry \& research design: Choosing among five approaches. Thousand Oaks, California: Sage Publications, Inc.

Denzin, N. (1978). The logic of naturalistic inquiry. In N. K Denzin (Ed.), Sociological methods: A sourcebook (2 ${ }^{\text {nd }}$ ed., pp. 6-29). New York: McGraw-Hill.

Derman-Sparks, L., Tanaka-Higa, C., Sparks, B. (n.d.). Children, race and racism: How race awareness develops. Retrieved from TeachingforChange.org: http:// www.teachingforchange.org/node/125.

Dileo, C. (2000). Ethical thinking in music therapy. Cherry Hill, NJ: Jeffrey Brooks.

Ferris, J. (1993). America's musical landscape. Madison, WI: Brown \& Benchmark.

Forrest, L. C. (2001). Addressing issues of ethnicity and identity in palliative care through music therapy practice. Voices: A World Forum for Music Therapy, 1(2). Retrieved from https:// normt.uib.no/index.php/voices/article/view/60/38.

Giorgi, A. (Ed.). (1985). Phenomenology and physiological research. Pittsburgh, PA: Duquesne University Press.

Grammy.com. (2012). Past winners search. Retrieved from http://www.grammy.com/nominees/ search

Hadley, S., \& Yancy, G. (Eds.). (2012). Therapeutic uses of Rap and hip-hop. New York, NY and Hove, East Sussex: Routledge Taylor \& Francis Group.

Hara, A. F. (2012). RAP (Requisite, ally, protector) and the desperate contemporary adolescent. In S. Hadley \& G. Yancy (Eds.), Therapeutic uses of Rap and hip-hop (pp. 3-25). New York, NY and Hove, East Sussex: Routledge Taylor \& Francis Group.

Jay-Z (2007). Intro. In Dyson, M.E. Know what I mean? Reflections on Hip Hop (pp. ix-xii). New York: Basic Civitas.

Kim, S. (2008). The supervisee's experience in cross-cultural music therapy supervision. In S. Hadley (Ed.), Qualitative inquiries in music therapy: A monograph series, 4. Gilsum, NH: Barcelona Publishers.

Korbin, C., \& Tyson, E. (2006). Thematic analysis of hip-hop music: Can hip-hop in therapy facilitate empathic connections when working with clients in urban settings? The Arts in Psychotherapy, 33(4), 343-356.

KRS-One, (2009). The gospel of Hip Hop: First instrument. New York: powerHouse. 
Levitin, D. J. (2008). The world in six songs. New York, NY: Penguin Group (USA) Inc. Lightstone, A. J. (2012). The importance of hip-hop for music therapists. In S. Hadley \& G. Yancy (Eds.), Therapeutic uses of Rap and hip-hop (pp. 39-51). New York, NY and Hove, East Sussex: Routledge Taylor \& Francis Group.

The Media Briefing. (2012). Music of the United States. Retrieved from TheMediaBriefing website: http:www.themediabriefing.com/issues/music-of-the-united-states.

Miller, T. E., \& Shahriari, A. (2009). World music: A global journey (2nd ed.). New York, NY: Routledge.

Morey, R. (1940). Upset in emotions. The Journal of Social Psychology, 12, 333-356.

Morrison, S. J., \& Demorest., S. M. (2009). Cultural constraints on music perception and cognition. In J. Y. Chiao (Ed.), Progress in brain research (Vol. 178, pp. 67-77). The Netherlands: Elsevier.

Nordoff, P., \& Robbins, C. (2007). Creative music therapy: A guide to fostering clinical musicianship (2nd ed.). Gilsum, NH: Barcelona Publishers.

Nzewi, M. (1999). Strategies for music education in Africa: Towards a meaningful progression from tradition to modern. International Journal of Music Education, 33, 72-87. doi:10.1177/025576149903300109.

Peretti, B. W. (2009). Lift every voice: The history of African American music. Lanham, MD: Rowman \& Littlefield Publishers, Inc.

Pavlicevic, M. (2003). Groups in music: Strategies from music therapy. London, England and Philidelphia, PA: Jessica Kinsgley Publishers Ltd.

Rilinger, R. L. (2011). Music therapy for Mexican American children: Cultural implications and practical considerations. Music Therapy Perspectives, 29, 78-85.

Sarrazin, N. (2006). India's music: Popular film songs in the classroom. Music Educator's Journal, 93(1).

Schwartz, E. K. (2008). Music, therapy, and early childhood: A developmental approach. Gilsum, NH: Barcelona Publishers.

Schwartz, E. K. (2012). You and me makes...we: A growing together songbook. Melrose, MA: Center for Early Childhood Music Therapy.

Starr, L., \& Waterman, C. (2009). American popular music: From minstrelsy to mp3. New York, NY and Cary, NC: Oxford University Press USA.

Stige, B. (2002). Culture-centered music therapy. Gilsum, NH: Barcelona Publishers.

Styles of R\&B. (n.d.). In About R\&B music. Retrieved from http://www.ehow.com/ about_5097616_rb-music.html

Swijghuisen Reigersberg, M. E. (2010). Applied ethnomusicology, music therapy and ethnographically informed choral education: The merging of disciplines during a case study in Hopevale, Northern Queensland. In K. Harrison, E. Mackinlay, \& S. Pettan (Eds.), Applied ethnomusicology: Historical and contemporary approaches (pp. 51-74). Newcastle, UK: Cambridge Scholars Publishing.

Trainor, L. J., \& Corrigall, K. A. (2010). Music acquisition and effects of musical experience. In M. R. Jones et. al. (Eds.), Music perception (Springer handbook of auditory research), 36, 89-120. doi. 10.1007/978-1-4419-6114-3_4 
U.S. Census Bureau. (2010). State \& county quickfacts. Retrieved from http:// quickfacts.census.gov/qfd/states/00000.html

Viega, M. (2012). The Hero's Journey in hip-hop and its applications in music therapy. In S. Hadley \& G. Yancy (Eds.), Therapeutic uses of rap and hip-hop (pp. 57-78). New York: Routledge.

Viega, M. (2013). “Loving me and my butterfly wings:” A study of hip-hop songs written by adolescents in music therapy (Doctoral Dissertation). Retrieved from ProQuest Dissertations and Theses. (UMI No. 3552365)

Wheeler, B. L., \& Baker, F. A. (2010). Influences of music therapists' worldviews on work in different countries. The Arts in Psychotherapy, 37, 215-227.

Williams, K., \& Abad, V. (2008). Reflections on music therapy with indigenous families: Cultural learning put into practice. Voices: A World Forum for Music Therapy, 8(1). Retrieved from https://normt.uib.no/index.php/voices/article/viewarticle/452/370

Yalom, I. D. (1995). The theory and practice of group psychotherapy (4th ed.). New York, NY: Basic Books. 
